Check for updates

The BMJ

Cite this as: $B M J 2020 ; 370: m 2681$ http://dx.doi.org/10.1136/bmj.m2681 Published: 03 July 2020

\section{Sixty seconds on ... NHS Charities Together}

\section{Abi Rimmer}

\section{That name sounds familiar}

You may have heard of it as the organisation that received the $€ 32 \mathrm{~m}(€ 36 \mathrm{~m}$; \$40m) raised by Captain Tom Moore. ${ }^{1}$ In total, £130m has been raised for NHS Charities Together during the covid-19 pandemic.

\section{Nice! But who are they?}

The organisation formerly known as the Association of NHS Charities is essentially an umbrella organisation for NHS charities. Your local trust, for example, might have its own charitable arm and that could be a member of NHS Charities Together.

\section{Could be?}

Yes, well membership isn't free. Depending on the income of the charity, annual membership costs between $£ 1000$ and $£ 5000 .^{2}$ NHS charities must be members to benefit from this covid-19 windfall. ${ }^{3}$

\section{That doesn't sound very charitable}

Perhaps not, but NHS Charities Together says that the fee contributes to running costs and member services. It also says that if an NHS charity is eligible to join and applies for a covid-19 grant then their first two years of membership will be deducted from that grant, meaning it is not out of pocket.

\section{But where is my donation going?}

Good question. There are 237 members of the organisation, ${ }^{4}$ an increase from 140 when its urgent covid-19 appeal was first launched on 23 March. Each of these member charities has been given an initial grant of £35 ooo.

\section{And the rest?}

A second wave of grants was awarded, this time based on $€ 7$ per staff member in the NHS trust or trusts that each charity supports. For example, £119 ooo went to Southampton Hospitals Charity and £147 ooo went to Nottingham Hospitals Charity.

\section{But what's it paying for?}

Money donated to NHS charities cannot be spent on direct patient care, so this money isn't paying for drugs or personal protective equipment. Instead, it's been used to buy things like wellbeing food boxes for staff, and computer tablets that allow patients to speak to their relatives.

\section{There must be money left over?}

So far, £2om has been distributed and £1om is available for charities to apply for by the end of August. The remainder of the money will be available to members through further waves of funding, so get in there quick, there's f10om to spend.

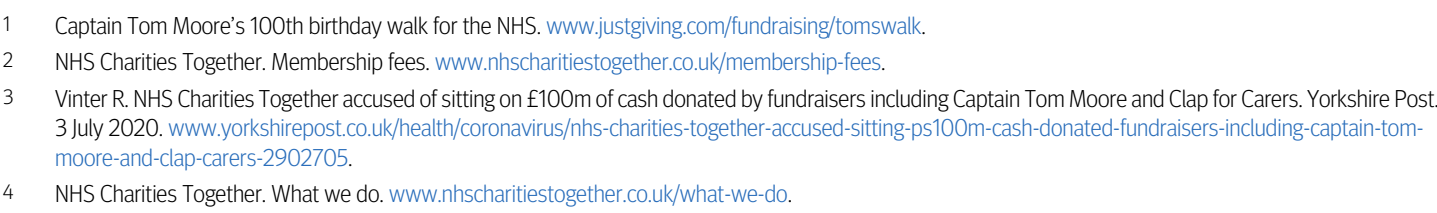

